\title{
PEMBUATAN SISTEM INFORMASI KOIN BOND DI PT SAGARA ASIA TECHNOLOGY MENGGUNAKAN SWIFT 4
}

\author{
(Production of Koin Bond Information System at PT Sagara Asia Technology \\ Using Swift 4)
}

\author{
Helmi Taufiq Al Hakim ${ }^{1}$, Galih Suryo², Sofiyanti Indriasari ${ }^{1}$ \\ ${ }^{1}$ Sekolah Vokasi Institut Pertanian Bogor, Jalan Kumbang No 14 Babakan, Bogor \\ ${ }^{2}$ PT Sagara Asia Technology, Jl. Kiara Sari Permai, Bandung
}

E-mail : sofiyanti@apps.ipb.ac.id

Diterima 3 Juni 2021/ Disetujui 28 Agustus 2021

\begin{abstract}
PT Sagara Asia Technology or better known as Sagara Technology is a company engaged in technology consulting and digital products. Sagara Technology manufactures and provides premium software development, training and talent products. The work done at Sagara Technology focuses on developing website technology and mobile applications. Investment is an option for many groups of people to invest in a company because investment promises long-term benefits. Therefore, PT Lunaria Annua Teknologi decided to create a Bond Coin application to reach all groups of people who want to invest and can take advantage of investment returns according to their wishes. The methodology used during the creation of this application is Scrum. Scrum is used as a framework because this methodology is suitable for small teams, clear application specifications and Scrum allows iteration and incremental of a product requirement that will be found during product development. Bond coins make it easier for investors to conduct checks on Government Securities purchased, including transparency, security and efficiency in transactions.
\end{abstract}

Keywords: application, Bond Coin, mobile, scrum

\section{PENDAHULUAN}

PT Sagara Asia Technology atau yang lebih dikenal dengan Sagara Technology merupakan sebuah perusahaan yang bergerak dalam bidang konsultan teknologi dan produk digital. Sagara Technology memproduksi dan menyediakan produk pengembangan perangkat lunak premium, pelatihan, dan talenta. Pekerjaan yang dikerjakan di Sagara Technology berfokus pada pengembangan teknologi website dan aplikasi mobile.

Sagara Technology sedang mengerjakan beberapa proyek untuk clientnya, salah satunya adalah PT Lunaria Annua Teknologi atau lebih dikenal dengan Koinworks. Koinworks merupakan perusahaan yang bergerak dalam bidang finansial meliputi pendanaan, pinjaman, sampai dengan trading. Saat ini Koinworks sedang dalam tahap pembuatan Financial Super App. Financial Super 
App milik Koinworks memiliki beberapa aplikasi di dalamnya antara lain; Koin Robo, Koin P2P, Koin Trade, Koin Gold, Koin Bisnis, Koin Pintar, Koin Revolving, dan Koin Legal. Pada saat ini aplikasi yang sedang dalam tahap pengembangan yaitu Koin Robo.

Koin Robo memiliki fitur bernama Koin Bond untuk menyediakan wadah bagi investor yang ingin membeli Surat Utang Negara sebagai investasinya. Untuk keamanan aplikasi ini, Koinworks telah bekerja sama dengan Kementerian Keuangan sebagai penyedia Surat Utang Negara yang akan diperjual belikan. Selain itu, terdapat Bina Artha Sekuritas untuk melindungi investor dari kejahatan dunia maya.

Koin Bond menyediakan digitalisasi jual beli Surat Utang Negara dengan tujuan untuk lebih memperluas basis investor di dalam negeri, mendukung terwujudnya masyarakat yang berorientasi pada investasi jangka menengah dan jangka Panjang. Dengan adanya Koin Bond tentu masyarakat dapat melakukan investasi. Melalui sistem yang terdapat pada aplikasi Koin Bond, masyarakat mendapatkan detail kupon Surat Utang Negara yang dibeli dan dapat melakukan pencairan dengan mudah serta aman. Dalam pembuatan Sistem Informasi Koin Bond berbasis mobile menggunakan bahasa pemrograman Swift 4 di PT Sagara Asia Technology dengan metode scrum dan teknologi MVC. Tahapan pada metode ini antara lain product backlog, sprint planning meeting, sprint backlog, dan lain-lain. Koin Bond diharapkan dapat memudahkan investor untuk melakukan pemeriksaan terhadap Surat Utang Negara yang dibeli mencakup transparansi, keamanan, dan efisiensi dalam bertransaksi.

\section{METODE PENELITIAN}

Metode yang digunakan untuk pembuatan sistem informasi Koin Bond berbasis mobile di PT Sagara Asia Technology adalah scrum. Metode ini dipilih sebagai kerangka kerja dalam penyelesaian pembuatan sistem informasi Koin Bond berbasis mobile di PT Sagara Asia Technology karena metode ini cocok digunakan pada tim yang berukuran kecil, spesifikasi yang sudah jelas dan metode ini memungkinkan adanya iterasi dan peningkatan terhadap suatu kebutuhan produk yang akan ditemukan selama pengerjaan produk, dan juga masa pengerjaan yang relatif cepat dan waktu yang telah ditentukan.

Metode scrum terbagi atas tiga roles yaitu Product Owner, Scrum Master, dan Development/Scrum Team. Product Owner ialah seorang yang memiliki tugas untuk mengatur urusan dengan stakeholder sedangkan Scrum Master mengurusi bagian internal, Development Team mengatur urusan teknis pengerjaan proyek dan pembahasan yang lebih rinci.

Scrum adalah sebuah kerangka kerja yang dapat menggunakan bermacam proses dan teknik di dalamnya. Scrum secara sistematis melakukan manajemen produk dan teknik kerja, sehingga dapat secara terus-menerus meningkatkan kinerja produk, tim, dan lingkungan kerja. Setiap komponen di dalam kerangka kerja ini memiliki tujuan tertentu dan sangat penting bagi 
keberhasilan penggunaan scrum (Schwaber dan Sutherland, 2017). Ilustrasi dari beberapa tahapan pengembangan prototipe dapat dilihat pada Gambar 1 .

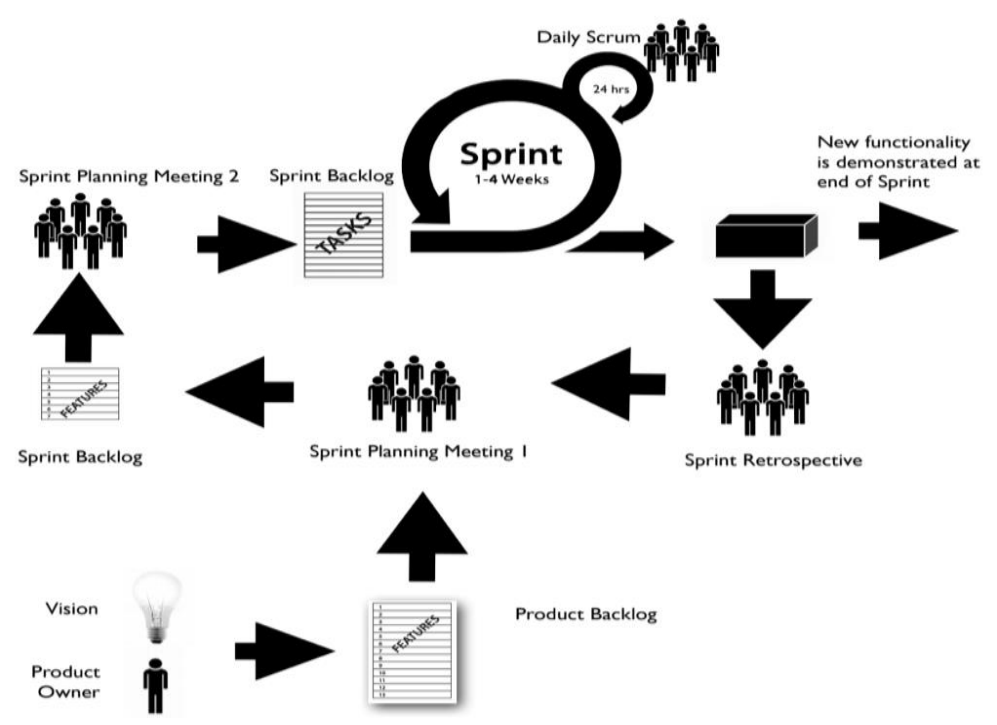

Gambar 1 Tahap Metodologi Scrum (Sutherland 2010)

\section{SCRUM TEAM}

Scrum Team merupakan kelompok yang dibuat untuk menjalankan metode scrum. Scrum Team ini bersifat lintas fungsi, yaitu memiliki semua keahlian yang dibutuhkan untuk menyelesaikan pekerjaan mereka tanpa bergantung kepada orang lain di luar tim ini (Schweber, 2013). Scrum Team menyelesaikan produk secara berkala dan bertahap untuk memaksimalkan peluang guna mendapatkan umpan balik. Pengembangan dan penyerahan secara bertahap dari sebuah produk yang "selesai", memastikan produk yang berpotensi dapat digunakan, selalu siap (Partogi 2015). Adapun anggota dari Scrum Team antara lain:

\section{Product Owner}

Product Owner atau pemilik proyek harus memastikan bahwa tim pengembang bekerja sesuai dengan target yang telah ditetapkan dilihat dari kacamata bisnis. Product Owner melakukan manajemen terhadap Product Backlog, yang di-breakdown menjadi to-do-list, sehingga semua keinginan dan kebutuhan sistem dapat terekam dengan baik berdasarkan keuntungan yang diterima dengan mempertimbangkan sisi bisnisnya. Product Owner fokus pada bagaimana produk dihasilkan nantinya. Selain itu Product Owner juga harus selalu melihat berapa banyak dana yang dikeluarkan dalam mengembangkan produk dan seberapa besar pendapatan yang dihasilkan oleh produk tersebut.

\section{Scrum Master}

Scrum Master merupakan orang yang bertanggung jawab untuk memimpin sebuah Scrum Team dan menyokong penggunaan scrum. Scrum Master bertanggung jawab untuk memastikan tujuan, ruang lingkup dan ranah produk dipahami sebaik mungkin oleh semua orang yang ada di dalam Scrum Team, 
menemukan teknik yang paling efektif untuk mengelola product backlog, membantu tim pengembang untuk menghasilkan produk bernilai bisnis tinggi, dan menghilangkan hambatan yang memperlambat perkembangan pekerjaan tim pengembang.

\section{Development Team}

Development Team atau tim pengembang terdiri dari para ahli profesi yang bekerja untuk menghasilkan potongan produk increment yang selesai dan berpotensi untuk dirilis pada setiap akhir sprint. Increment yang selesai wajib tersedia pada saat sprint review. Hanya anggota tim pengembang yang membuat peningkatan ini. Product Owner dan Scrum Master tidak termasuk dalam tim ini, kecuali mereka turut serta dalam mengerjakan pekerjaan dari sprint backlog.

\section{METODE PENELITIAN}

\section{Product Backlog}

Product Owner menyusun dan mengumpulkan semua permintaan dan kebutuhan sistem. Setelah tujuannya sudah ditetapkan, semua permintaan dan kebutuhan tersebut dibagi-bagi menjadi bagian-bagian kecil yang mana setiap bagian kecil tersebut harus mempunyai nilai dan layak untuk dikembangkan. Product backlog berada dalam tanggung jawab Product Owner suatu produk, mulai dari isinya, ketersediaannya, hingga urutannya. Product Owner juga menentukan skala prioritas dalam pengerjaan bagian-bagian kecil tersebut.

\section{Sprint Planning Meeting}

Pekerjaan yang akan dikerjakan pada tahapan sprint direncanakan pada saat sprint planning. Perencanaan ini dilakukan secara kolaboratif oleh seluruh anggota Scrum Team. Sprint planning memiliki batasan waktu maksimal delapan jam untuk tahapan sprint yang berdurasi satu bulan. Scrum Master memastikan selama tahapan sprint ini dilaksanakan dengan baik dan memastikan peserta memahami tujuannya. Scrum Master membimbing Scrum Team untuk menjaganya di dalam batasan waktu. Pada proses analisis, tim pengembang melakukan pemodelan sistem yang akan dibuat berupa perancangan konsep database, dan pemodelan sistem yang menggunakan Unified Modelling Language (UML) seperti use case diagram, use case description, class diagram, dan activity diagram.

\section{Database}

Database adalah sekumpulan file yang saling berhubungan dan terorganisir yang umumnya disimpan dan diakses secara elektronik dari suatu sistem komputer (Sutarman 2012).

\section{Unified Modelling Language (UML)}

Unified Modelling Language (UML) adalah 'bahasa' pemodelan untuk sistem atau perangkat lunak yang berparadigma "berorientasi objek". 
Pemodelan sesungguhnya digunakan untuk penyederhanaan permasalahanpermasalahan yang kompleks sedemikian rupa sehingga lebih mudah dipelajari dan dipahami (Nugroho 2010). UML terdiri atas :

\section{a. Use Case Diagram}

Use Case Diagram digunakan untuk memenuhi satu atau lebih kebutuhan pengguna yang akan menggunakan sistem. Use case menangkap bagian fungsional yang disediakan oleh sistem. Sebuah use case merepresentasikan sebuah interaksi antar aktor yang terlibat dengan sistem (Miles, 2006).

\section{b. Class Diagram}

Class Diagram memiliki hubungan antar class yang saling berinteraksi di dalam suatu sistem. Setiap garis yang terhubung di antara class disebut dengan association. Setiap association memiliki konsep yang dinamakan multiplicity, karena setiap association secara umum bersifat bidirectional yang berarti antar class memiliki hubungan timbal balik (Whitten dan Bentley, 2012).

\section{c. Activity Diagram}

Activity Diagram menggambarkan berbagai kegiatan user atau sistem, orang yang melakukan setiap aktivitas, dan alur kegiatan secara berurutan (Satzinger, Jackson dan Burd; 2012).

\section{Sprint Backlog}

Sprint backlog adalah daftar product backlog item yang terpilih untuk sprint ditambahkan perencanaan untuk menghantarkan increment dan mencapai sprint goal. Sprint backlog adalah prakiraan dari Development Team mengenai fungsionalitas yang akan masuk ke dalam increment berikutnya dan pekerjaan yang perlu dikerjakan untuk menghantarkan fungsionalitasnya menjadi increment yang "Selesai".Sprint backlog menampilkan seluruh pekerjaan yang perlu dikerjakan untuk mencapai sprint goal.

\section{Sprint}

Sprint adalah kerangka waktu yang berdurasi maksimal satu bulan untuk mengembangkan produk yang berpotensi untuk dirilis. Sprint berfokus pada pengiriman produk berdasarkan item yang dipilih dari product backlog yang masuk ke dalam sprint backlog. Sprint biasanya terdiri dari implementasi product backlog item yang telah ditetapkan dalam waktu sprint planning meeting. Pada tahap ini juga dilakukan penentuan teknologi yang akan dipakai dalam pembuatan sistem.

\section{Daily Scrum}

Scrum team harus melakukan pertemuan harian yang berdurasi maksimal 15 menit per harinya. Hal ini dilakukan dengan tujuan untuk sinkronisasi 
perkembangan hasil pekerjaan, mengidentifikasi masalah dan menyelesaikan masalah yang ada selama mengerjakan pekerjaannya.

\section{Sprint Review}

Setiap sprint selalu berakhir dengan mempresentasikan fitur-fitur yang telah dikerjakan. Hal tersebut dilakukan untuk memastikan bahwa fitur-fitur tersebut dapat bekerja dengan baik. Selain itu juga dilakukan pengujian terhadap sistem yang telah dibuat apakah sistem sudah dianggap selesai atau belum. Metode pengujian yang digunakan yaitu metode black box. Metode black box merupakan metode pengujian sistem yang pengujiannya diturunkan dari spesifikasi program dan menguji fungsi sistem beserta pengujian yang bertentangan dengan cara kerja sistem.

\section{Finished Work}

Suatu sprint yang pengerjaannya telah selesai dan sudah dilaksanakan demo produk maka produk akan segera dirilis. Produk harus melewati tahap sprint dengan baik dan benar terlebih dahulu sebelum produk tersebut diberikan status finished work. Pada akhir sprint, increment dari semua item pada product backlog yang dijalankan pada semua sprint dan harus bernilai "selesai", yang artinya berfungsi sesuai dengan ekspektasi.

\section{Sprint Retrospective}

Harapan yang ingin dicapai pada sprint retrospective adalah adanya perbaikan tindakan sehingga sprint berikutnya dapat dikerjakan dengan lebih baik lagi. Perbaikan-perbaikan tersebut harus diimplementasikan pada sprint berikutnya atau pada proyek selanjutnya.

\section{HASIL DAN PEMBAHASAN}

\section{Bahan dan Metode}

Metode yang digunakan untuk pembuatan Sistem Informasi Koin Bond berbasis Mobile di PT Sagara Asia Technology adalah Scrum. Metode ini dipilih sebagai kerangka kerja dalam penyelesaian pembuatan Sistem Informasi Koin Bond berbasis mobile di PT Sagara Asia Technology karena metode ini cocok digunakan untuk berukuran kecil, spesifikasi yang sudah jelas dan metode ini memungkinkan adanya iterasi dan incremental terhadap suatu kebutuhan produk yang akan ditemukan selama pengerjaan produk, dan juga masa pengerjaan yang relatifb cepat dan waktu yang sudah ditentukan.

Dalam metode Scrum terbagi dalam tiga bagian, yang pertama adalah Product Owner, Scrum Master, dan Development/Scrum Team. Product Owner ialah seseorang yang memiliki tugas untuk mengatur urusan dengan stakeholder sedangkan Scrum Master mengatur bagian internal, Development Team mengatur urusan teknis pengerjaan proyek dan pembahasan yang lebih rinci.

Scrum adalah sebuah kerangka kerja yang dapat menggunakan bermacam proses dan teknik di dalamnya. Scrum mengekspos melakukan manajemen produk dan teknik kerja, sehingga dapat secara terus-menerus meningkatkan 
kinerja produk, tim, dan lingkungan kerja. Kerangka kerja Scrum terdiri dari Scrum Team dan peran-peran, acara-acara, artefak-artefak dan aturan-aturan terkait. Setiap komponen di dalam kerangka kerja ini memiliki tujuan tertentu dan sangat penting bagi keberhasilan penggunaan Scrum (Schwaber \& Sutherland, 2017). Ilustrasi dari beberapa tahapan pengembangan prototipe dapat dilihat pada Gambar 2.

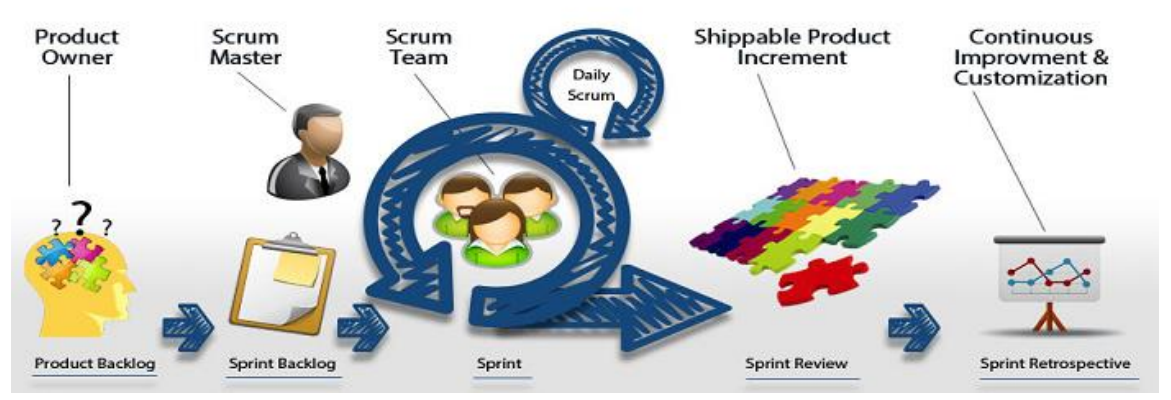

Gambar 2 Tahap Metodologi Scrum

\section{Hasil dan Pembahasan}

Pembuatan Sistem Informasi Koin Bond merupakan sistem informasi berbasis mobile yang bertujuan agar memudahkan pengguna dalam berinvestasi pada Surat Utang Negara. Proses Pembuatan Sistem Informasi Koin Bond Berbasis Mobile di PT Sagara Asia Technology menggunakan bahasa pemrograman Swift 4. Swift 4 digunakan untuk pengembangan aplikasi di dalam platform khusus produk-produk Apple inc. Swift didesain untuk berdampingan dengan Objective- $C$ dan menghindari program kode yang salah. Dalam Pembuatan Sistem Informasi Koin Bond Berbasis Mobile di PT Sagara Asia Technology menggunakan metode scrum.

\section{Product Backlog}

Pembuatan sistem ini terdiri dari 13 product backlog yang datanya didapat dari user story yang disusun oleh product owner sesuai prioritasnya. Product backlog ini dikerjakan tiga sprint. Product baklog pada sistem dibuat dapat dilihat pada Tabel 1.

\section{Sprint}

Dalam sprint dilakukan beberapa kegiatan di antaranya, yaitu:

1. Sprint planning meeting yaitu tahap perencanaan untuk kegiatan sprint selanjutnya. Sprint development yaitu tahap melakukan implementasi dari sprint backlog

2. Sprint meeting.

3. Sprint review adalah proses melakukan pengujian dari implementasi yang dilakukan pada sprint development. 
4. Sprint retrospective yaitu tahap evaluasi dari proses berjalannya satu sprint yang telah dilalui.

Tabel 1 Product Backlog

\begin{tabular}{|c|c|c|c|c|}
\hline No & Aktifitas & $\begin{array}{l}\text { Urutan } \\
\text { Aktifitas }\end{array}$ & Deskripsi & $\begin{array}{l}\text { Urutan } \\
\text { Prioritas }\end{array}$ \\
\hline \multirow{3}{*}{1} & \multirow{3}{*}{ SID } & 1 & Investor dapat melakukan registrasi & 1 \\
\hline & & 2 & $\begin{array}{l}\text { Investor dapat melihat Detail data diri } \\
\text { yang didaftarkan }\end{array}$ & 2 \\
\hline & & 3 & $\begin{array}{l}\text { Investor menunggu aktivasi SID oleh } \\
\text { Kemenkeu }\end{array}$ & 3 \\
\hline \multirow{6}{*}{2} & \multirow{6}{*}{ Product } & 4 & Investor dapat melihat List Product & 4 \\
\hline & & 5 & Investor dapat melihat Detail Product & 5 \\
\hline & & 6 & $\begin{array}{l}\text { Investor dapat melakukan pembelian } \\
\text { Product }\end{array}$ & 6 \\
\hline & & 7 & Investor melakukan Checkout Product & 7 \\
\hline & & 8 & $\begin{array}{l}\text { Investor dapat melakukan pencairan } \\
\text { SUN }\end{array}$ & 8 \\
\hline & & 9 & $\begin{array}{l}\text { Investor dapat melakukan penjualan ke } \\
\text { Secondary Market }\end{array}$ & 9 \\
\hline \multirow{4}{*}{3} & \multirow{4}{*}{ Portofolio } & 10 & Tampilan Dashboard/Portofolio & 10 \\
\hline & & 11 & $\begin{array}{l}\text { Investor dapat melihat Summarry } \\
\text { Product }\end{array}$ & 11 \\
\hline & & 12 & $\begin{array}{l}\text { Investor dapat melihat detil semua } \\
\text { product yang telah dibeli }\end{array}$ & 12 \\
\hline & & 13 & $\begin{array}{l}\text { Investor dapat melihat alur } \\
\text { keuangannya }\end{array}$ & 13 \\
\hline
\end{tabular}

\section{Sprint Pertama}

Sprint pertama dilakukan pada proses implementasi item product backlog dari urutan prioritas nomor 1-3 dengan durasi pengimplementasian 14 hari $\times 9$ jam. Dari implementasi tersebut sekaligus melakukan perancangan class diagram, activity diagram, usecase diagram, merancang user interface, dan mengimplementasikan user interface yang sudah terancang dalam code. Pada sprint pertama ini menghasilkan class diagram dan use case diagram. Berikut lampiran beberapa hasil dari sprint pertama.

Pada Gambar 3, salah satu use case yang terdapat dalam Pembuatan Sistem Informasi Koin Bond. Pada Gambar 4 merupakan class diagram Pembuatan Sistem Informasi Koin Bond. 


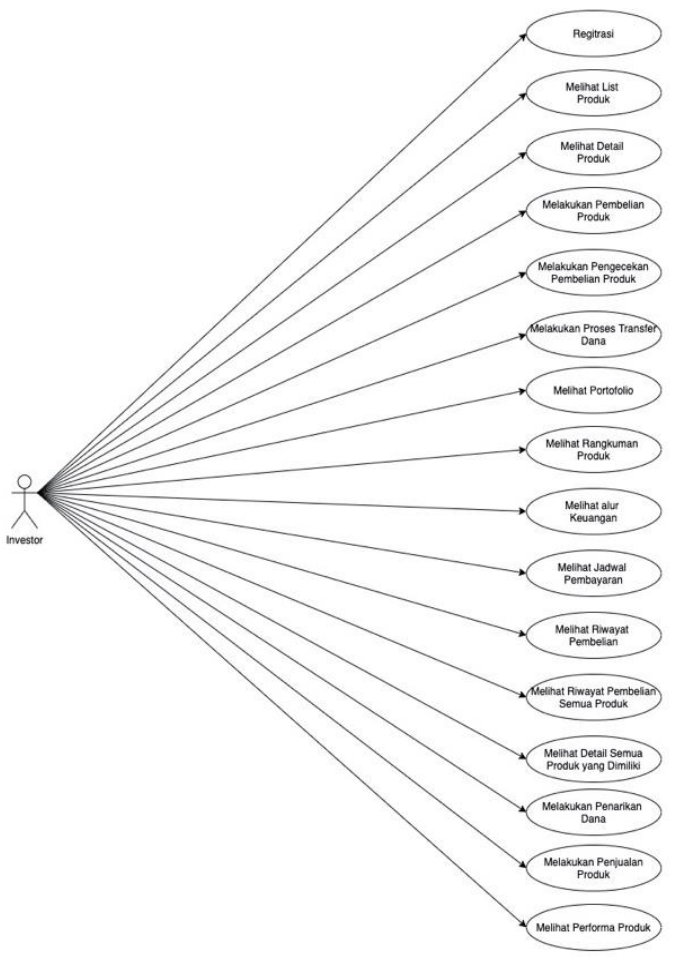

Gambar 3 Use Case Diagram

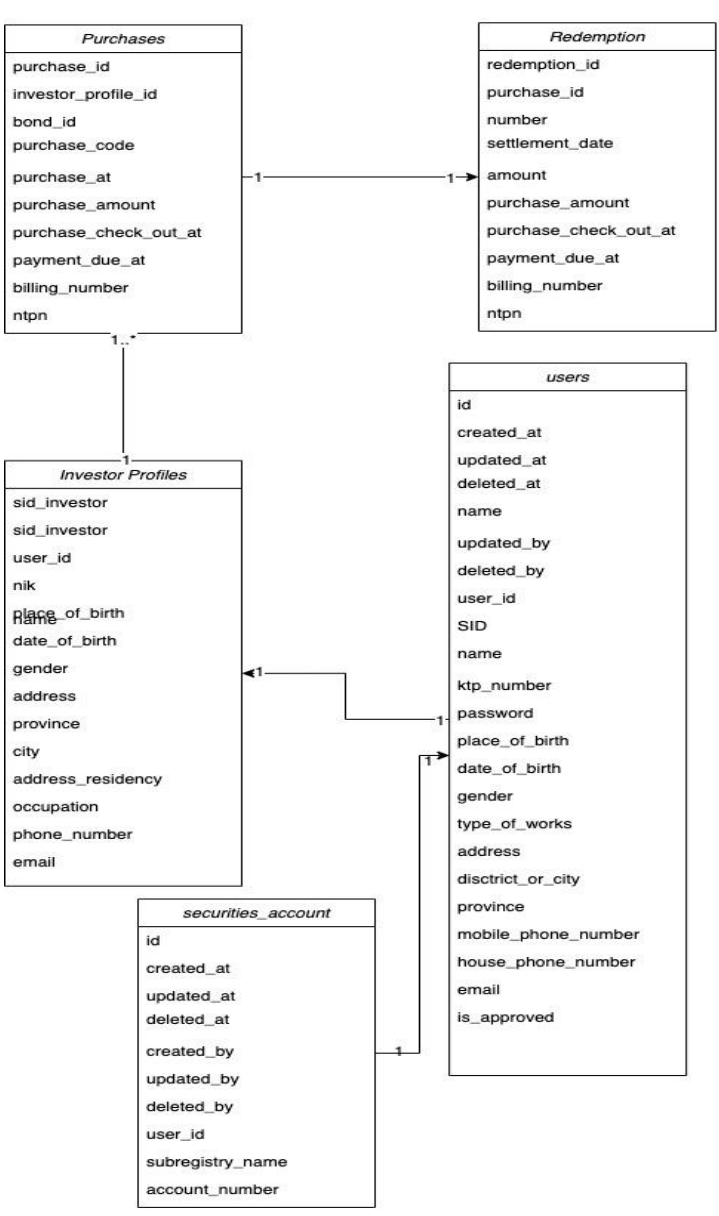

\begin{tabular}{|l|}
\hline \multicolumn{1}{|c|}{ user_detail } \\
\hline id \\
created_at \\
updated_at \\
deleted_at \\
first_name \\
last_name \\
investor_maiden_mothers_name \\
religion \\
gender \\
birth_place \\
birth_date \\
email \\
mobile_phone \\
phone_number \\
nationality \\
id_card_number \\
marital_status \\
spouse_name \\
npwp_number \\
id_card_address_address_id_card \\
id_card_address_id_card_city \\
id_card_address_id_card_province \\
id_card_address_id_card_postal_code \\
id_card_address_id_card_country \\
address_address_id_card \\
address_id_card_province \\
address_id_card_postal_code \\
address_id_card_country \\
education_background \\
investor_occupation \\
inverstor_occupation_others \\
company_name \\
company_address \\
company_city \\
investor_position \\
investor_nature_of_business \\
investor_income_per_annum \\
investor_fund_source \\
investor_investement_objective \\
asset_owner \\
investor_bank_acoount \\
investor_bank_number \\
\hline
\end{tabular}

Gambar 4 Class Diagram 


\section{Sprint Kedua}

Sprint kedua dilakukan pada proses implementasi item product backlog dari urutan prioritas nomor 4-9 yang kemudian dimasukkan ke sprint backlog. Dari implementasi tersebut sekaligus melakukan perancangan activity diagram dan use case description dari daftar sprint backlog yang sudah ditentukan kemudian melakukan pengimplementasian dari tiap activity diagram dan use case description kedalam code. Pada sprint kedua ini menghasilkan activity diagram dan use case description. Berikut lampiran hasil dari sprint kedua. Pada Gambar 5 merupakan salah satu activity diagram.

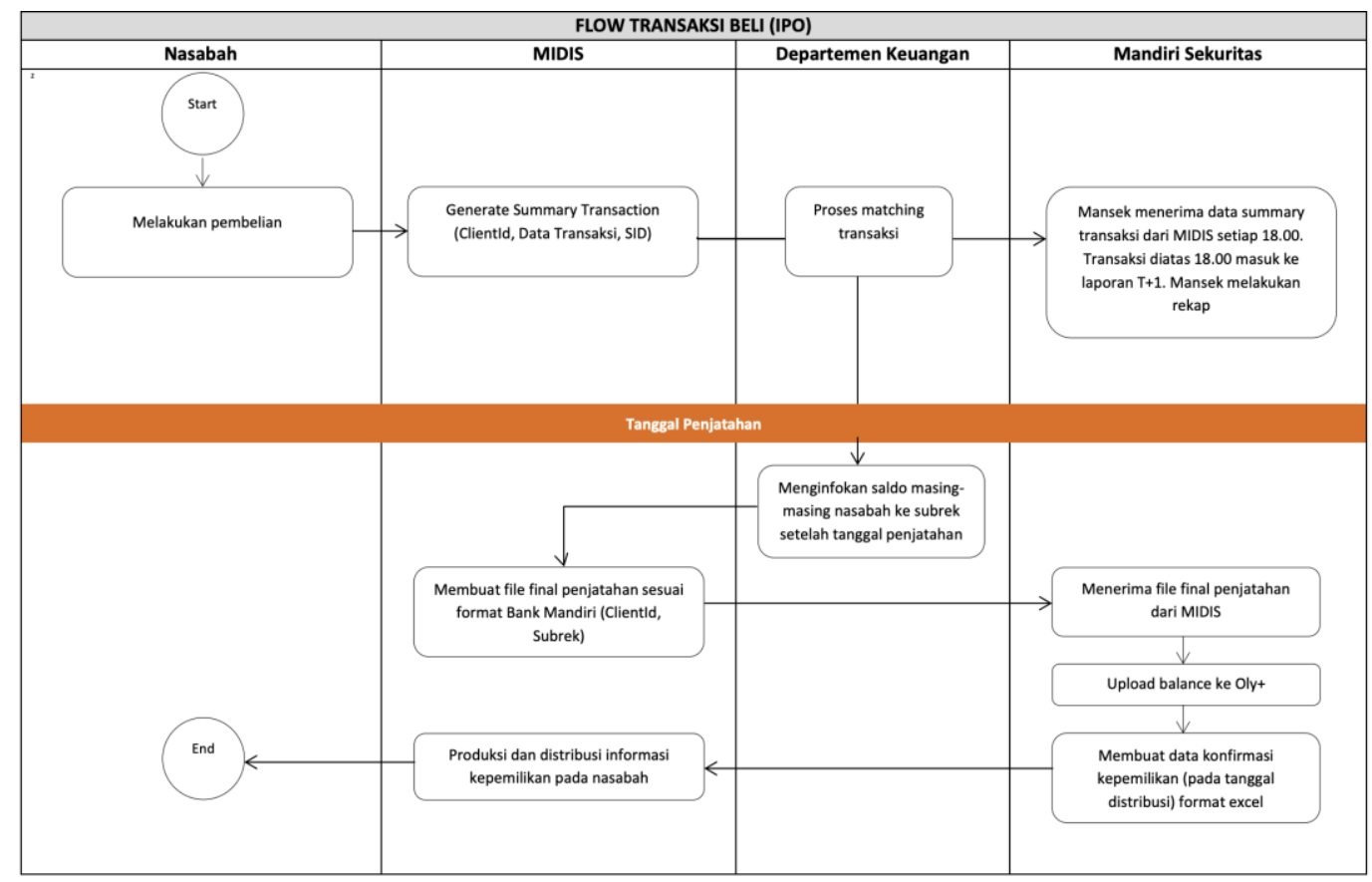

Gambar 5 Activity Diagram

\section{Sprint Ketiga}

Sprint ketiga dilakukan pada proses implementasi item product backlog dari urutan prioritas nomor 10-13 yang kemudian dimasukkan kedalam sprint backlog. Dari implementasi tersebut sekaligus melakukan perancangan activity diagram dan use case description dari daftar sprint backlog yang sudah ditentukan kemudian melakukan pengimplementasian dari tiap activity diagram dan use case description kedalam code. Pada sprint ketiga ini menghasilkan activity diagram dan use case description.

\section{Finished Work}

Dari ketiga sprint yang telah dilakukan, tahap akhir yang dilakukan yaitu finished work yaitu berupa penyerahan aplikasi kepada pihak product owner Selain itu dilakukan juga demo aplikasi kepada Core Team PT Lunaria Annua Teknologi atau yang lebih dikenal dengan Koinworks yang akan menggunakan sistem informasi Koin Bond. Pada Gambar 6 merupakan contoh tampilan dari sistem informasi Koin Bond. 


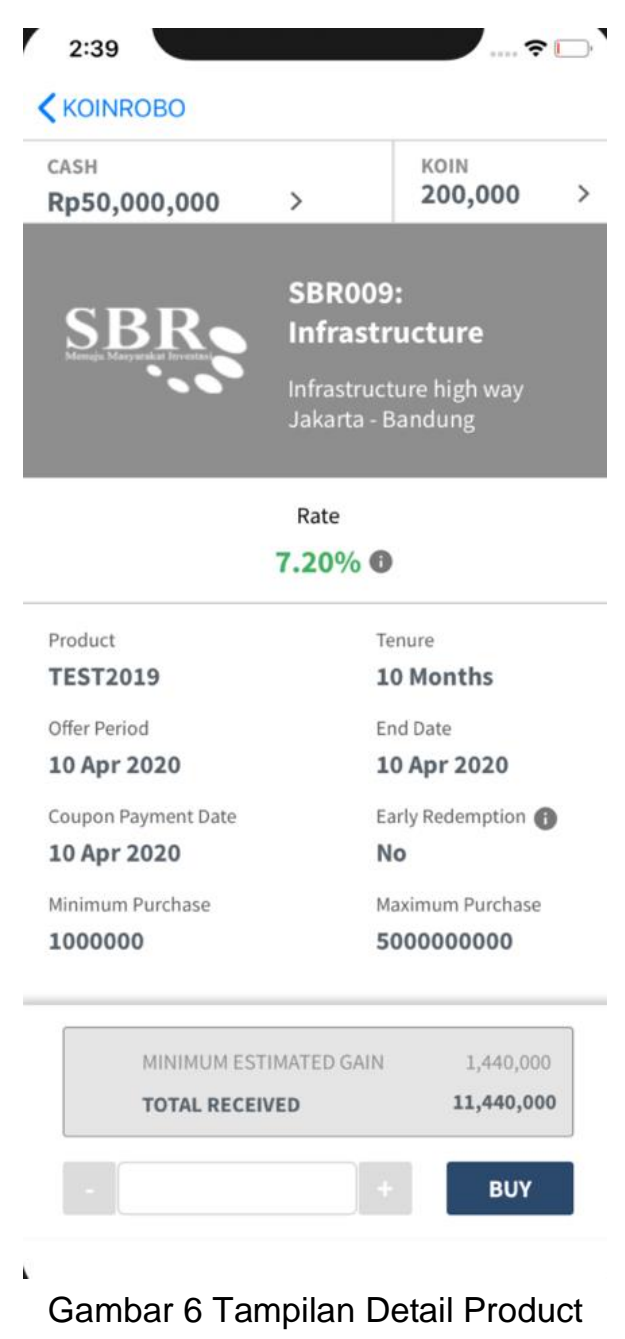

\section{SIMPULAN}

Pembuatan Sistem Informasi Koin Bond Berbasis Mobile di PT Sagara Asia Technology dikembangkan dengan metodologi scrum. Setelah melakukan pengembangan sistem melalui tahapan sprint, dapat disimpulkan bahwa :

1. Sistem Informasi Koin Bond dapat digunakan untuk berinvestasi dengan cara membeli Surat Utang Negara dengan memanfaatkan fitur pendaftaran SID yang langsung terkoneksi dengan Kemenkeu.

2. Fitur Pendaftaran SID user pada Sistem Informasi Koin Bond yang langsung terkoneksi dengan Kemenkeu telah berhasil dibuat .

\section{SARAN}

Saran yang dapat diberikan agar sistem ini dapat berjalan dengan baik dan masukan untuk berjalannya sistem ini selanjutnya, yaitu kesepakatan antara PT Sagara Asia Technology dengan client harus lebih dipertegas agar kesepakatan 
awal lebih terjaga dan proyek dapat selesai lebih cepat sesuai dengan waktu yang ditentukan. Penambahan tenaga kerja agar proyek yang dikerjakan dapat selesai lebih cepat.

\section{DAFTAR PUSTAKA}

Apple Inc. 2014. The Swift Programming Language (Swift 5.2).

Bohon C. 2019. Apples Swift Programming Language The Smart Persons Guide [Internet]. [diakses 2020 April 8]. Tersedia pada: https://www.techrepublic.com/article/apples-swift-programming-languagethe-smart-persons-guide/

Christmantara V. 2013. Metodologi Scrum [Internet]. [diunduh 2020 April 9]. Tersedia pada: https://www.academia.edu/10042923/Metodologi_SCRUM_-_Paper

Febiharsa D, Made I, Hudallah N. 2018. Uji Fungsionalitas (Blackbox Testing) Sistem Informasi Lembaga Sertifikasi Profesi (SILSP) Batik dengan Appperfect Web Test dan Uji Pengguna. Joined Journal. 1(2):117-126.

Schwaber K, Sytherland J. 2017. The Scrum Guide [Internet]. [diunduh 2020 April 9]. Tersedia pada:

https://www.scrumguides.org/docs/scrumguide/v2017/2017-ScrumGuideUS.pdf\#zoom=100

Schwaber K, Sutherland J. 2011. Panduan Scrum [Internet]. [diunduh 2020 Maret 10]. Tersedia pada:

https://www.scrumguides.org/docs/scrumguide/v1/Scrum-Guide-ID.pdf Sutherland J. 2010. Scrum Handbook. Orlando [US]: Scrum Training Institute. 